\title{
MENINGKATKAN KARAKTER MENGHORMATI ORANG TUA LEWAT PENDIDIKAN AGAMA KRISTEN UNTUK ANAK USIA SEKOLAHDASAR
}

\author{
Santia, ${ }^{1}$ Tarisih,${ }^{2}$ Lionarto Erson Jayadi ${ }^{3}$ \\ Sekolah Tinggi Teologi Moriah, Indonesia ${ }^{12}$ \\ Sekolah Tinggi Teologi Widya Agape, Indonesia ${ }^{3}$ \\ Email: tarisih2014@gmail.com²
}

\begin{abstract}
It is very important for children to have character in respecting their parents. In the formation of the child's character certainly does not happen by itself, but needs the help of others. Not only parents, Christian religious education, has an important role in shaping the character of children. The formation of character through school should also be considered in school, education is not only about subjects that only focus on the acquisition of cognitive abilities but also the cultivation of Christian values. In this paper, the author uses the method of literature study in solving the problem of how to increase the character of respect for parents through Christian religious education for primary school children. The results of this study are respect for parents is an attitude that needs to be instilled in elementary school children, so that they can socialize well in society. Character education for elementary school children through Christian religious education is the key in changing the younger generation for the better.
\end{abstract}

Keywords: Character Education, Respecting Parents, Christian Religious Education

\begin{abstract}
Abstrak
Penting sekali untuk anak mempunyai karakter dalam menghormati orang tua. Dalam pembentukan karakter anak tentu tidak terjadi dengan sendirinya, melainkan butuh bantuan orang lain. Bukan hanya orang tua, pendidikan agama Kristen, punya peran penting dalam membentuk karakter anak-anak. Pembentukan karakter melalui sekolah juga harus di perhatikan di sekolah, pendidikan tidak semata-mata tentang mata pelajaran yang hanya mementingkan diperolehnya kemampuan kognitif tetapi juga penanaman nilai-nilai kristiani. Dalam tulisan ini

penulis menggunakan metode studi pustaka dalam memecahkan permasalahan mengenai bagaimana meningkatkan karakter menghormati orang tua lewat pendidikan agama Kristen untuk anak sekolah dasar. Hasil penelitian ini adalah menghormati orang tua merupakan sikap yang perlu ditanamkan ke anak Sekolah Dasar, sehingga mereka dapat bersosialisasi dengan baik di masyarakat. Pendidikan karakter pada anak Sekolah Dasar lewat pendidikan agama Kristen menjadi kunci dalam perubahan generasi muda yang lebih baik.
\end{abstract}

Kata kunci: Pendidikan Karakter, Menghormati Orang Tua, Pendidikan Agama Kristen 


\section{PENDAHULUAN}

Pendidikan karakter di nilai sangat penting untuk ditanamkan pada anak-anak Sekolah Dasar karena pendidikan karakter adalah proses pendidikan yang ditujukan untuk mengembangkan nilai, sikap, dan perilaku yang memancarkan akhlak mulia atau budi pekerti luhur. Pendidikan karakter di programkan dan dilakukan tidak hanya di gereja, ${ }^{1}$ tetapi juga di sekolah. Di zaman sekarang ini sering kita jumpai anak muda yang kurang menghormati orang tuanya. Mereka suka sekali melawan dan menentang nasihat orangtua yang dianggap kuno, lalu mereka pun memilih menjalani hidup sekehendak hati karena merasa diri sudah besar. Bagi seorang anak, menghormati orang tua adalah kewajiban, dan merupakan perintah Tuhan yang harus ditaati, bahkan termasuk dalam satu dari sepuluh hukum Tuhan. "Hormatilah ayahmu dan ibumu, supaya lanjut umurmu di tanah yang diberikan Tuhan, Allahmu, kepadamu." (Keluaran 20:12). Terhadap anak yang menghormati orangtuanya saja Tuhan menyediakan berkat-berkat-Nya, terlebih-

\footnotetext{
${ }^{1}$ Imron Widjaja, Bobby Kurnia Putrawan, Hengki Wijaya. "Manajemen Pendidikan Agama Kristen Melalui Pelayanan Penggembalaan Dalam Kelompok Sel." EDUKASI: Jurnal Penelitian Pendidikan Agama dan Keagamaan 18, no.2 (2020): 159-170. https://doi.org/10.32729/edukasi.v18i2.689.
}

lebih terhadap anak yang mau membalas budi dan berbuat baik kepada orangtuanya. Karena itu selagi orangtua kita masih hidup hormatilah dan perlakukan mereka dengan dilandasi oleh kasih Kristus. ${ }^{2}$ Kalau ada orang Kristen yang tidak menghormati orangtuanya, berlaku kurang ajar, apalagi sampai menelantarkan orangtuanya, ya telah melanggar firman Tuhan.

Menghormati orang tua bukan sematamata karena mereka telah mencukupi semua yang kita butuhkan, atau dengan harapan supaya mendapatkan warisan. Kalau demikian maka kasih seperti itu adalah kasih yang tidak tulus karena disertai dengan motivasi terselubung. Menghormati orangtua harus dengan kasih yang tulus di segala keadaan. Sekalipun mereka tidak mampu memberikan apa yang kita perlukan sepenuhnya, sebagai anak, kita harus tetap menghormati dan mengasihi orangtua kita. ${ }^{3}$ Dalam bukunya Etika Praktis, Budyapranata Al menuliskan, "Orang tua wajib kita

\footnotetext{
${ }^{2}$ Sutrisno dan Christiani Hutabarat. "Orangtua Dan Teman Bermain Terhadap Perkembangan Sosial Anak (Parents and Playing Friends Toward Children Social Development)." QUAERENS: Journal of Theology and Christianity Studies 1, no.1 (2019): 2855. https://doi.org/10.46362/quaerens.v1i1.15.

${ }^{3}$ Daniel Tanamal, Ini Alasan Mengapa Kita Menghormati Orangtua. (Jurnal Videi: https://www.jawaban.com/read/article/id/2016/04/28/ 63/160420231524 ini 28 April 2016. / diakses 18 November 2021 pukul 14:38 WITA).
} 
hormati karena merekalah yang menjadi perantara hidup kita (menjamin hidup kita), yang mendidik serta mengarahkan hidup kita sebagai manusia". Budyapranata juga mengatakan bahwa "penghormatan kepada orang tua bukan hanya masalah pujian dan sopan santun saja, melainkan penghargaan dan ketaatan, selama bimbingan dan perintah tersebut membawa pada hal-hal yang positif dan tidak melanggar kebenaran firman Tuhan". 4 Menghormati orang tua sangat penting, karena orang tua sudah mendidik dan membesarkan anak-anak. Menghormati orang tua juga merupakan salah satu kewajiban yang perlu ditanamkan kepada anak ${ }^{5}$ khususnya di sekolah dasar.

Menurut Pieget, siswa sekolah dasar berusia antara 7-13 tahun berada pada fase operasional konkret dan operasional formal. Pendidikan karakter sangat perlu dan penting dilakukan mulai usia di sekolah dasar. Seperti pendapat yang disampaikan oleh Ali Mustadi yaitu mengingat pentingnya penanaman karakter di usia sekolah dasar dan mengingat usia sekolah dasar merupakan masa awal pembentukan

\footnotetext{
${ }^{4}$ Budyapranata Al. Etika Praktis, (Yogyakarta: Andi, 1987), 18.

${ }^{5}$ Christiani Hutabarat dan Bobby Kurnia Putrawan. "Pengantar Pola Asuh Orang Tua Dalam Keluarga Kristen." PNEUMATIKOS: Jurnal Teologi Kependetaan 11, no.2 (2021): 84-94. https://stapin.ac.id/ejournal/index.php/pneumatikos/article/view/28.
}

diri, maka penanaman karakter yang baik di usia sekolah dasar merupakan hal yang sangat penting untuk dilakukan. ${ }^{6}$ Artinya bahwa pendidikan karakter di Sekolah Dasar masih sangat mudah dibentuk, dan dibimbing.

Penulis menggunakan metode studi pustaka untuk memecakan permasalahan dalam penelitian ini. Sumber primer seperti buku, jurnal ilmiah, artikel, dimanfaatkan untuk membangun konsep tentang peranan guru pendidikan agama Kristen dalam pembentukan karakter anak berdasarkan pendidikan agama Kristen. Penulis melakukan analisis secara induktif, melalui beberapa tahapan yakni, reduksi data, penyajian data, verifikasi dan penarikan kesimpulan. ${ }^{7}$ Di dalam penulis akan menyimpulkan seluruh rangkaian penelitian pustaka sebagai jawaban atas pertanyaan penelitian.

\section{PEMBAHASAN}

Pendidikan karakter adalah suatu sistem penamaan nilai-nilai karakter yang meliputi komponen pengetahuan, kesadaran atau kemauan, dan tindakan untuk melaksanakan

\footnotetext{
${ }^{6}$ Fatmawati Dwi Rohmah, Pentingnya Pendidikan Karakter Pada Siswa Sekolah Dasar Untuk Memperbaiki Moral Generasi Bangsa, (https://r.search.yahoo.com/ Oktober 2017 / diakses 05 November 2021 pukul 12:18 WITA), 2-3.

${ }^{7}$ Sugiyono, Metode penilitian Kombinasi, (Bandung: Alfabeta, 2011), 339-343
} 
nilai-nilai tersebut, baik terhadap Tuhan Yang Maha Esa, diri sendiri, sesama, lingkungan, maupun kebangsaan. Pengembangan karakter bangsa dapat dilakukan melalui perkembangan karakter individu seseorang. Akan tetapi, karena manusia hidup dalam lingkungan sosial dan budaya tertentu, maka perkembangan karakter individu seseorang hanya dapat dilakukan dalam lingkungan sosial dan budaya yang bersangkutan. Artinya, perkembangan budaya dan karakter dapat dilakukan dalam suatu proses pendidikan yang tidak melepaskan peserta didik lingkungan sosial, budaya masyarakat, dan budaya bangsa. Lingkungan sosial dan budaya bangsa adalah Pancasila, jadi pendidikan budaya dan karakter adalah mengembangkan nilai-nilai Pancasila pada diri peseta didik melalui pendidikan hati, otak, dan fisik.

Pendidikan karakter atau pendidikan watak sejak awal munculnya pendidikan oleh para ahli dianggap sebagai suatu hal yang niscaya. John Dewey, misalnya, pada tahun 1916 yang mengatakan bahwa sudah merupakan hal yang lumrah dalam teori pendidikan bahwa pembentukan watak merupakan tujuan umum pengajaran dan pendidikan budi pekerti di sekolah. Pendidikan ke arah terbentuknya karakter bangsa para siswa merupakan tanggungjawab semua guru. Oleh karena itu, pembinaannya pun harus oleh guru. ${ }^{8}$

Pendidikan karakter di Sekolah Dasar selain dapat membangun karakter anak, juga dapat memberikan kesan menyenangkan bagi siswa, karena dalam menanamkan pendidikan karakter setiap sekolah mempunyai cara masing-masing dan disesuaikan dengan karakteristik siswa di sekolah dasar. Kemudian pendidikan karakter ini sangat diperlukan agar generasi bangsa dapat menghadapi keadaan di era global ini. Beberapa karakter yang perlu ditanamkan pada siswa yaitu religius, kemandirian, tanggung jawab, kejujuran, amanah, kerja keras, cinta tanah air, hormat dan santun, dermawan, suka menolong, gotong royong, percaya diri, kreatif, dan pekerja keras, kepemimpinan dan keadilan.

Pendidikan karakter bukanlah tanggung jawab segelintir orang atau lembaga tertentu saja. Pelaksanaan pendidikan karakter adalah tanggung jawab bersama, baik lingkungan keluarga, sekolah, dan masyarakat. Ketiga lingkungan pendidikan tersebut harus bekerja bersama-sama untuk mendukung konsistensi dan kontinuitas

\footnotetext{
${ }^{8}$ Nopan Omeri. "Pentingnya Pendidikan Dalam Dunia Pendidikan," Manajer Pendidikan 9, no.3 (Juli 2015): 464-468. https://ejournal.unib.ac.id/index.php/manajerpendidik an/article/view/1145/0.
} 
pendidikan karakter, sehingga dapat tercapai tujuan yang telah ditetapkan. ${ }^{9}$

Masa emas (golden age) pada perkembangan pada usia Sekolah Dasar harus menjadi perhatian yang serius di kalangan pendidik utama yaitu orang tua. Sebab masa ini adalah masa yang mudah membentuk keperibadian anak. Sebagai figur utama orang tua berperan dalam membentuk kepribadian anak menjadi percaya diri atau nminder. Peran orang tua dalam membangun kepercayaan diri anak adalah menjadi pendengar yang baik, menunjukkan sikap menghargai, memberi kesempatan untuk membantu, melatih kemandirian anak, membantu anak agar lebih optimis, memupuk minat dan bakat anak, mengajak memecahkan masalah, mencari cara untuk membantu sesama, memberi kesempatan anak berkumpul bersama orang dewasa dan mengarahkan agar dapat mempersiapkan masa depan. ${ }^{10}$

Dalam pembentukan karakter anak bukan hanya guru saja yang bertanggung jawab dalam membentuk karakter anak, tetapi ini adalah tugas semua lembaga, baik

\footnotetext{
${ }^{9}$ Wuri Wuryandani, Bunyamin Maftuh, Sapriya, dan Dasim Budimansyah, Pendidikan Karakter Disiplin di Sekolah Dasar, (Cakrawala Pendidikan, N0.2 Juni 2014 ) 286-288.

${ }^{10}$ Muzdalifah M. Rahman, Peran Orang Tua Dalam Membangun Kepercayaan Diri Pada Anak Usia Dini, 2, No.2, (Juli-Desember 2014): 1.
}

keluarga atau pun masyarakat. Membentuk karakter anak lebih mudah dilakukan ketimbang membentuk karakter orang dewasa. Hal ini dikarenakan secara kognitif anak-anak masih belum berfikir secara abstrak ketimbang orang tua. Dari tempat ini para orangtua Kristen mempunyai suatu tanggung jawab yang besar dalam membesarkan anak-anak dan menanamkan ke dalam pikiran yang masih muda itu kebenaran tentang benar dan salah." Orangtua adalah wakil Tuhan di rumah, sehingga ketika anak melihat orangtua anak melihat Allah." 11

Teori perkembangan kognitif yang dikemukakan oleh Piaget menyatakan bahwa anak usia sekolah dasar pada umumnya berada pada tahap operasional konkret untuk anak dengan rentang usia 7 sampai 11 tahun. Tahap operasional konkret merupakan tahap ketiga dari tahap-tahap perkembangan kognitif menurut Piaget. Selama masa sekolah dasar terjadi perkembangan kognitif yang pesat pada anak. Anak mulai belajar membentuk sebuah konsep, melihat hubungan, dan memecahkan masalah pada situasi yang

\footnotetext{
${ }^{11}$ Mary Setiawani dan Stephen Tong, Seni Membentuk Karakter Kristen (Jakarta : Lembaga Reformed Injili Indonesia,1995), 98.
} 
melibatkan objek konkret dan situasi yang tidak asing lagi bagi dirinya. ${ }^{12}$

Anak wajib dan harus bersikap sopan terhadap orang tuanya, sebab orang tua adalah orang yang lebih tua dari pada anak dan juga merupakan wakil Tuhan di dunia ini. Orang tualah yang memerantarai dan mengenalkan seorang anak pada Tuhannya. Hormat kepada orang tua tampak sangat sepele. Namun, konsep menghormati orang tua atau orang yang lebih tua bisa jadi tidak menghormati orang tua atau yang lebih tua bisa jadi tidak mengerti dan diresapi dalamdalam oleh anak kita karena kita sendiri sebabagi orang tua jarang memberi pengertian terdalam mengenai konsep "hormat". 13

Sikap menghormati orang yang lebih tua terdapat aspek kognitif yang dapat membentuk sikap. Di sisi lain terdapat subjek yang memiliki pandangan bahwa sikap menghormati orang yang lebih tua itu wajib dan penting karena memang sikap menghormati orang yang lebih tua itu

\footnotetext{
${ }^{12}$ Rima Trianingsih, pengantar praktik mendidik anak usia sekolah dasar, Al Ibtida 3, no.2 (Oktober 2016): 197-216. 10.24235/al.ibtida.snj.v3i2.880.

${ }^{13}$ T.A. Tatang Utomo, Mencegah Dan Mengatasi Krisis Anak Melalui Pengembangan Sikap Mental Orang Tua, (Jakarta : Gramedia Widiasrana Indonesia, 2005), 3 173-174; Bobby Kurnia Putrawan dan Ramot Peter. "Misi di Tengah Krisis Multidimensi." Jurnal Teologi Gracia Deo 2, no.2 (2020): 70-79. https://doi.org/10.46929/graciadeo.v2i2.38
}

merupakan cerminan masyarakat Indonesia. Hal ini sesuai dengan pendapat Walgito di dalam tulisan jurnal Fivien yang menyatakan bahwa komponen kognitif (komponen perseptual), yaitu komponen yang berkaitan dengan pengetahuan, pandangan, keyakinan, yaitu hal-hal yang berhubungan dengan bagaimana orang memberikan persepsi terhadap obyek sikap. Pada komponen sikap yang kedua, yakni komponen afektif subjek rata-rata menasakan rasa janggal ketika tidak menerapkan sikap menghormati di kehidupan sehari harinya. Menurut Walgito di dalam tulisan jurnal Fivien menyebutkan bahwa sikap menghormati kepada orang yang lebih tua memiliki 6 faktor yang mempengaruhi, yaitu pengalaman pribadi, kebudayaan, orang lain yang dianggap penting, media masa, institusi pendidikan dan agama, faktor emosi dalam diri. ${ }^{14}$

Membentuk karakter anak didik peranan guru dalam keberhasilan peserta didik sangat penting maka hendaknya guru mampu beradaptasi dengan berbagai perkembangan yang ada dan meningkatkan kompetensinya sebab guru pada saat ini bukan saja sebagai pengajar, tetapi juga sebagai pengelola proses belajar mengajar.

\footnotetext{
${ }^{14}$ Fivien Luthfia Rahmi Wardani Zahrotul Uyun, Menghormati Orang Yang Lebih Tua Pada Remaja Etnis Jawa, Indigenous: (Jurnal Ilmiah Psikologi Vol. 2 No. 2 2017),178-179.
} 
Salah satu tugas yang dilaksanakan guru disekolah adalah memberikan pelayanan kepada siswa agar mereka menjadi peserta didik yang selaras dengan tujuan sekolah. Guru harus mampu membawa anak didik memahami serta menjalankan nilai-nilai agama yang dipelajarinya dengan mengandalkan kemampuan dan karakter yang tinggi dan mengacu pada sosok Yesus sebagai guru yang Agung. Sebagai guru yang mengajar di bidang Pendidikan Agama Kristen, harus mampu menjadi garam dan terang dunia (Mat. 5:13-16). Lebih jauh, Lickona menekankan tiga hal dalam mendidik karakter. Tiga hal itu dirumuskan dengan indah: knowing, loving, and acting the good. Menurutnya keberhasilan pendidikan karakter dimulai dengan pemahaman karakter yang baik, mencintainya, dan pelaksanaan atau peneladanan atas karakter baik itu. ${ }^{15}$

Menuntun anak didik melalui Pendidikan Agama Kristen konteks sekolah dan jemaat agar mengalami perjumpaan pribadi dengan Yesus Kristus dan menikmati hidup bersama Roh Kudus, menjadikan pendekatan olah pikir, olah hati, olah rasa dan olah raga sebagaimana disinggung di

15 Thomas Lickona, Educating For Character: How Our School Can Teach Respect and Responsibility, (New York: Bantam Books, 1992), 1222. atas, lebih efektif dan bermakna. Membesarkan anak adalah suatu tugas istimewa yang diberikan Allah, dan yang menuntut persiapan matang dan juga komitmen untuk membina satu keluarga yang takut akan Allah dibutuhkan kesabaran, kerajinan, ketekunan dan pengertian tentang beberapa prisip dasar alkitabiah". 16

Pakar teologi dan pendidikan warga jemaat, Wright, mengusulkan sebuah pendekatan pendidikan karakter yang dinamainya model lima saluran, yakni: pertama, saluran Kitab Suci (scripture); kedua, saluran cerita-cerita di masyarakat dan konteks budaya (stories); ketiga, saluran contoh, model, atau teladan (examples); keempat, saluran komunitas pendukung (community); dan kelima, saluran praktik, perbuatan, tindakan konkrit (practices). ${ }^{17}$ Secara sederhana, aplikasinya dapat dijelaskan sebagai berikut. Seandainya guru PAK mengajak murid belajar sebuah karakter, maka mereka dapat menempuh salah satu atau bahkan semua saluran tadi.

Dalam pendidikan agama Kristen, peran guru meningkatkan karakter menghormati

\footnotetext{
${ }^{16}$ Paulina Tiendas, Orangtua \& Anak-Anak Rencana Allah Bagi Keluarga (Bandung: Yayasan Kalam Hidup, 1996), 23

${ }^{17}$ Binsen S. Sidjabat, Penguatan Guru Pak Untuk Pendidikan Karakter: Melihat Kontribusi Seri Selamat, (Vol.3, Nomor 1, Januari 2019), 33-34
} 
orang tua lewat pendidikan agama Kristen untuk anak usia sekolah dasar, sangat penting dalam membantu mengembangkan karakter peserta didik. Karena peranan guru adalah sebagai pengajar dan pembimbing dalam kegiatan proses pembelajaran kepada peserta didik. Adapun dipengaruhi oleh berbagai factor, seperti motivasi, kematangan, hubungan peserta didik dengan guru, kemampuan verbal, tingkat kebebasan, rasa aman dan keterampilan guru dalam berkomunikasi. Jika faktor-faktor di atas dipenuhi, maka melalui pembelajaran peserta didik dapat belajar dengan baik.

Guru harus berusaha membuat sesuatu menjadi jelas bagi peserta didik dan terampil dalam memecahkan masalah ${ }^{18}$ Oleh karena itu, tugas guru hanya menerapkan dan memotivasi siswa dalam membentuk karakter, agar siswa mengerti betapa pentingnya menghormati orang tua. Guru ini sebagai penanggung jawab dalam mengontrol kedisiplinan anak, supaya anak tersebut mengerti dan memahami setiap tingkat laku terhadap orang tua. Setiap orang tua, menghendaki anak-anaknya mendapat pendidikan yang bermutu.

Guru merupakan orang yang dipercayakan Tuhan dalam melaksanakan

\footnotetext{
${ }^{18}$ Ajisaka, Bimbingan Belajar Anak, Jakarta: Wahyumedia, 2019, 3
}

pendidikan dan pengajaran sesuai dengan karunia yang telah diberikan kepadanya. "Guru adalah salah satu komponen manusiawi dalam proses belajar mengajar, yang ikut berperan dalam usaha pembentukan sumber daya manusia yang potensial dalam bidang pembangunan". ${ }^{19}$ Selain itu guru sebagai unsur manusiawi dalam pendidikan. "Guru adalah figur manusia sumber yang menempati posisi dan memegang peranan penting dalam pendidikan". ${ }^{20}$

\section{KESIMPULAN}

Meningkatkan karakter menghormati orang tua lewat pendidikan agama Kristen untuk anak usia sekolah dasar merupakan hal yang sangat penting dibangun kepada anak-anak. Hal ini diperlukan karena anak adalah supaya mereka memiliki karakter yang baik dan sesuai dengan kehidupan bermasyarakat. Sikap menghormati orang yang lebih tua terdapat dalam aspek kognitif yang dapat membentuk sikap. Di sisi lain terdapat subjek yang memiliki pandangan bahwa sikap menghormati orang yang lebih tua itu wajib dan penting karena memang

\footnotetext{
${ }^{19}$ Sardiman. Interaksi dan Motivasi BelajarMengajar. (Jakarta: PT. Raja Grafindo Persada 2007.), 125.

${ }^{20}$ Syaiful Bahri Djamarah, Guru Dan Anak Didik Dalam Interaksi Edukatif. (Jakarta: PT. Renika Cipta 2005), 1.
} 
sikap menghormati orang yang lebih tua itu merupakan cerminan masyarakat Indonesia. Melalui pendidikan agama Kristen, guru diharapkan dapat membimbing serta mengajarkan karakter yang seturut dan serupa dengan Yesus Kristus. Orang tua adalah wakil Tuhan di dunia selama anak-

\section{KEPUSTAKAAN}

Ajisaka, Bimbingan Belajar Anak, Jakarta: Wahyumedia, 2019.

Al, Budyapranata. Etika Praktis. Yogyakarta: Andi, 1987.

Djamarah, Syaiful Bahri. Guru Dan Anak Didik Dalam Interaksi Edukatif. Jakarta: PT. Renika Cipta, 2005.

Dwi Rohmah, Fatmawati, Pentingnya Pendidikan Karakter Pada Siswa Sekolah Dasar Untuk Memperbaiki Moral Generasi Bangsa (2021). https://r.search.yahoo.com/Oktober 2017, diakses 05 November 2020.

Hutabarat, Christiani dan Bobby Kurnia Putrawan. "Pengantar Pola Asuh Orang Tua Dalam Keluarga Kristen." PNEUMATIKOS: Jurnal Teologi Kependetaan 11, no.2 (2021): 84-94. https://stapin.ac.id/ejournal/index.php/pneumatikos/article/v iew/28

Lickona Thomas. Educating For Character: How Our School Can Teach Respect and Responsibility. New York: Bantam Books, 1992.

Omeri, Novan. "Pentingnya Pendidikan Dalam Dunia Pendidikan.” Manajer Pendidikan 9, no.1 (2015): 464-468. https://ejournal.unib.ac.id/index.php/ma najerpendidikan/article/view/1145/0.

Putrawan, Bobby Kurnia dan Ramot Peter. "Misi di Tengah Krisis Multidimensi." Jurnal Teologi anak masih dalam proses pertumbuhan, oleh sebab itu kesadaran dalam menghormati orang tua perlu ditanamkan sehingga generasi berikutnya dapat menghidupi dan mengaplikasikan dalam kehidupan anak tentang karakter menghormati orangtua.

Gracia Deo 2, no.2 (2020): 70-79. https://doi.org/10.46929/graciadeo.v2 i2.38

Rahman, Muzdalifah M. Peran Orang Tua Dalam Membangun Kepercayaan Diri Pada Anak Usia Dini. EDUKASIA: Jurnal Penelitian Pendidikan Islam 8, no.2 (2013): 373-388. http://dx.doi.org/10.21043/edukasia.v $8 \mathrm{i} 2.759$.

Sardiman. Interaksi dan Motivasi BelajarMengajar. Jakarta: PT. Raja Grafindo Persada, 2007.

Sidjabat, Binsen S. Penguatan Guru Pak Untuk Pendidikan Karakter: Melihat Kontribusi Seri Selamat, 3, no 1 (2019): 30-48. https://doi.org/10.46445/ejti.v3i1.121

Sugiyono. Metode penilitian Kombinasi. Bandung, Alfabeta, 2011.

Sutrisno dan Christiani Hutabarat. "Orangtua Dan Teman Bermain Terhadap Perkembangan Sosial Anak (Parents and Playing Friends Toward Children Social Development)." QUAERENS: Journal of Theology and Christianity Studies 1, no.1 (2019): 2855. https://doi.org/10.46362/quaerens.v1i1.15

Tong, Stephen dan Mary Setiawani Seni Membentuk Karakter Kristen. Jakarta: Lembaga Reformed Injili Indonesia, 1995.

Tanamal, Daniel. Ini Alasan Mengapa Kita Menghormati Orangtua. 2016. 
https://www.

jawaban.com/read/article/id/2016/04/28

/63/160420231524 ini alasan mengapa

kitaharus menghormati_orangtua.

diakses 18-11-2021.

Trianingsih Rima. "Pengantar Praktik

Mendidik Anak Usia Sekolah Dasar,"

Al Ibtida 3, no.2 (2016): 197-216.

10.24235/al.ibtida.snj.v3i2.880.

Tiendas Paulina. Orangtua \& Anak-Anak

Rencana Allah Bagi Keluarga.

Bandung: Yayasan Kalam Hidup, 1996.

Utomo, T.A. Tatang. Mencegah Dan

Mengatasi Krisis Anak Melalui

Pengembangan Sikap Mental Orang

Tua, Jakarta: Gramedia Widiasrana

Indonesia, 2005.

Wardani, Fivien, Luthfia Rahmi, dan Zahrotul Uyun. "Menghormati Orang Yang Lebih Tua Pada Remaja Etnis
Jawa," Indigenous: Jurnal Ilmiah Psikologi 2, no.2 (2017): 176-183.

https://doi.org/10.23917/indigenous.v2i 2.5681 .

Widjaja, Imron, Bobby Kurnia Putrawan, dan Hengki Wijaya. "Manajemen Pendidikan Agama Kristen Melalui Pelayanan Penggembalaan Dalam Kelompok Sel." EDUKASI: Jurnal Penelitian Pendidikan Agama dan Keagamaan 18, no.2 (2020): 159-170. https://doi.org/10.32729/edukasi.v18i2. 689.

Wuryandani, Wuri, Bunyamin Maftuh, Sapriya, dan Dasim Budimansyah. "Pendidikan Karakter Disiplin di Sekolah Dasar," Cakrawala Pendidikan, no.2 (2014): 286-295. http://dx.doi.org/10.21831/cp.v2i2.2168. 